\title{
In vitro antifungal susceptibility profiles and genotypes of 308 clinical and environmental isolates of Cryptococcus neoformans var. grubii and Cryptococcus gattii serotype B from north-western India
}

Correspondence Anuradha Chowdhary dranuradha@hotmail.com

Received 13 December 2010 Accepted 7 March 2011

\author{
Anuradha Chowdhary, ${ }^{1}$ Harbans Singh Randhawa, ${ }^{1}$ Gandhi Sundar, ${ }^{1}$ \\ Shallu Kathuria, ${ }^{1}$ Anupam Prakash, ${ }^{1}$ Ziauddin Khan, ${ }^{2}$ Sheng Sun ${ }^{3}$ \\ and Jianping $\mathrm{Xu}^{3}$ \\ ${ }^{1}$ Department of Medical Mycology, Vallabhbhai Patel Chest Institute, University of Delhi, \\ Delhi 11007, India \\ ${ }^{2}$ Mycology Reference Laboratory, Department of Microbiology, Faculty of Medicine, \\ Kuwait University, Safat, Kuwait \\ ${ }^{3}$ Institute of Infectious Disease Research, Michael G. DeGroote School of Medicine, \\ and Department of Biology, McMaster University, Hamilton, ON L8S 4K1, Canada
}

Cryptococcus neoformans and Cryptococcus gattii are aetiological agents of cryptococcosis, a major opportunistic systemic mycosis of increasing global importance. This study reports the antifungal susceptibility profiles of clinical and environmental isolates of C. neoformans var. grubii, genotype VNI/AFLP1 $(n=246)$, and C. gattii serotype B, genotype VGI/AFLP4 $(n=62)$, originating from patients and environmental sources in north-western India. All of the $C$. neoformans var. grubii and C. gattii isolates were mating type $\alpha$. Using the broth microdilution method, both species were found to be susceptible to the antifungals tested except for two clinical C. neoformans var. grubii isolates that were resistant to 5 -flucytosine (MIC $>64 \mu \mathrm{g} \mathrm{ml}^{-1}$ ). Data on the geometric mean of MICs revealed that $C$. gattii was significantly less susceptible than C. neoformans var. grubii to fluconazole, itraconazole and voriconazole $(P<0.0001)$. In addition, the $\mathrm{MIC}_{90}$ of $C$. gattii was twofold higher than that of $C$. neoformans var. grubii for fluconazole, itraconazole and voriconazole. However, no statistically significant difference in susceptibility of the two Cryptococcus species was observed against amphotericin B and 5-flucytosine. Furthermore, the environmental C. neoformans var. grubii isolates were significantly less susceptible to fluconazole, itraconazole and 5-flucytosine $(P<0.0001)$ than the clinical isolates. A continued surveillance of antifungal susceptibility of clinical and environmental strains of C. neoformans and C. gattii is desirable to monitor the emergence of any resistant strains in order to ensure more successful therapy of cryptococcosis.

\section{INTRODUCTION}

Cryptococcosis is a life-threatening, opportunistic fungal infection of worldwide distribution, including India, especially in the human immunodeficiency virus (HIV) positive population (Casadevall \& Perfect, 1998; Chakrabarti et al., 2000; Khanna et al., 2000; Lakshmi

Abbreviations: AFLP, amplified fragment length polymorphism; CLSI, Clinical and Laboratory Standards Institute; GM, geometric mean.

The GenBank/EMBL/DDBJ accession numbers for the URA5 sequences of the $C$. gattii isolates determined in this study are FJ604536-FJ604593 and HM059634-HM059637. et al., 2007; Thakur et al., 2008). It has two major aetiological agents, namely Cryptococcus neoformans and Cryptococcus gattii. C. neoformans has serotypes A, D and $\mathrm{AD}$, whereas C. gattii has serotypes B and C. The strains belonging to serotype A represent C. neoformans var. grubii, whereas those of serotype D represent $C$. neoformans var. neoformans. C. neoformans and C. gattii differ significantly with regard to their geographical distribution and ecological niches (Casadevall \& Perfect, 1998; Kwon-Chung et al., 2002). Based on molecular studies, using PCR fingerprinting, amplified fragment length polymorphism (AFLP) analysis, analysis of the orotidine monophosphate pyrophosphorylase (URA5) and phospholipase (PLB1) 
genes by RFLP and multilocus sequence typing, C. neoformans and C. gattii have been further classified into several distinct genotypes: VNI/AFLP1 and VNII/AFLP1A/AFLP1B (C. neoformans var. grubii, serotype A), VNIV/AFLP2 (C. neoformans var. neoformans, serotype D), VNIII/AFLP3 (hybrid serotype AD), VGI/AFLP4, VGII/AFLP6, VGIII/ AFLP5, VGIV/AFLP7 and AFLP10 (C. gattii, serotype B/C). In addition, hybrids of $C$. neoformans var. neoformans and $C$. gattii and of C. neoformans var. grubii and C. gattii belong to genotypes AFLP8 and AFLP9, respectively.

The vast majority of cryptococcal infections, particularly in immunocompromised patients, are caused by C. neoformans, whereas $C$. gattii accounts for a smaller proportion of cases, often occurring in immunocompetent patients in tropical and subtropical regions. However, in the past decade, a more virulent genotype of C. gattii, VGIIa/VGIIc, has emerged as a primary pathogen on Vancouver Island and its adjoining areas in Canada and the USA, indicating extension of its geographical domain to the temperate climate (Kidd et al., 2004; Byrnes et al., 2010). The outbreak of human and animal cryptococcosis on Vancouver Island due to $C$. gattii indicated that exposure to environmental sources such as colonized trees and soil led to pulmonary and disseminated cryptococcosis. In India, we have reported a widespread colonization of decayed wood inside trunk hollows of diverse tree species by $C$. neoformans var. grubii and C. gattii serotype B (Randhawa et al., 2006, 2008; Hiremath et al., 2008). The objective of this study was to compare antifungal susceptibility profiles of clinical isolates with those of environmental isolates of C. neoformans var. grubii and $C$. gattii serotype B originating from decayed wood of diverse tree species and from their surrounding soil in northwestern India.

\section{METHODS}

Fungal isolates. Three hundred and eight isolates, comprising 246 C. neoformans var. grubii and 62 C. gattii serotype B, originating from clinical and environmental sources were included in the study. All of the C. neoformans isolates $(n=246)$ were serotype A, genotype VNI/ AFLP1 and mating type $\alpha$, whereas all of the C. gattii isolates belonged to serotype B, genotype VGI/AFLP4 and mating type $\alpha$. Of the $246 C$. neoformans var. grubii isolates, 160 were clinical, originating from 130 patients, and the remaining 86 were from decayed wood of trees and soil. Among the 62 C. gattii isolates, 60 were from environmental and two were from clinical sources. The clinical isolates had been collected from 2002 to 2009 from various hospitals in the Union Territories of Delhi and Chandigarh, and the states of Uttar Pradesh and Himachal Pradesh. Of the 162 clinical isolates, $140(86 \%)$ originated from cerebrospinal fluid, 11 (7\%) from blood, seven (4\%) from sputum, three $(2 \%)$ from urine and one $(1 \%)$ from an endotracheal secretion. Of these, $109(67 \%)$ isolates were obtained from initial clinical specimens from patients with cryptococcosis, whereas 53 (33\%) were repeat isolations (two or more isolates from an individual patient collected at least 1 month apart) after the patients were put on amphotericin B or fluconazole therapy. The number of isolates obtained from $92 \mathrm{HIV}$-positive patients was 116 (72\%), whereas 21 isolates $(13 \%)$ were from 15 HIV-negative patients. The HIV status of the 25 patients yielding the remaining isolates of $C$. neoformans var. grubii was unknown.

Among the 146 environmental isolates, 86 (59\%) were C. neoformans var. grubii and $60(41 \%)$ were C. gattii serotype B. They had been collected and stocked during our investigation of decayed wood inside trunk hollows of a wide spectrum of tree species and soil samples in proximity to some of the positive trees (Randhawa et al., 2006, 2008; Hiremath et al., 2008). Also included for comparison were eight reference strains procured from global culture collections. These were C. neoformans (serotype A) ATCC 90112, C. gattii (serotype B) CBS1930 and CDC 3175 (Centers for Disease Control and Prevention, Atlanta), C. gattii (serotype B) B4495 and B4499 and C. gattii (serotype C) B4546, JF109 and JF101 (McMaster University, Hamilton, Ontario, Canada).

All isolates of C. neoformans var. grubii and C. gattii tested here were identified by standard mycological procedures (Randhawa et al., 2006, 2008; Hiremath et al., 2008). Their genotypes were determined based on two methods: (i) PCR fingerprinting using (GACA) 4 and M13 phage core sequences as single primers (Meyer et al., 1999); and (ii) DNA sequences at the URA5 locus (Meyer et al., 2009). The mating type of isolates was determined by PCR amplification, using primer pairs designed from the sequences of the mating type-specific STE12 and STE20 genes (Hiremath et al., 2008).

Antifungal susceptibility testing. In vitro antifungal susceptibility testing was carried out using the Clinical and Laboratory Standards Institute (CLSI) broth microdilution method (CLSI, 2008). The antifungal drugs tested were amphotericin B (Sigma), fluconazole, voriconazole (Pfizer), itraconazole (LeePharma) and 5-flucytosine (Sigma). Stock solutions were prepared in water (fluconazole and 5flucytosine) or DMSO (itraconazole, voriconazole and amphotericin B). Further dilutions of each antifungal agent were prepared with RPMI 1640 with glutamine without bicarbonate (Sigma), buffered to pH 7 with $0.165 \mathrm{M}$ MOPS (Sigma). The drug dilutions were dispensed in 96-well microdilution plates, sealed and frozen at $-70{ }^{\circ} \mathrm{C}$ until needed. The final concentrations of the drugs ranged from 0.125 to $64 \mu \mathrm{g} \mathrm{ml}^{-1}$ for fluconazole and 5-flucytosine, 0.03 to $16 \mu \mathrm{g} \mathrm{ml} \mathrm{g}^{-1}$ for amphotericin B and 0.015 to $8 \mu \mathrm{g} \mathrm{ml} \mathrm{m}^{-1}$ for itraconazole and voriconazole. The yeast inoculum was adjusted to a concentration of $0.5 \times 10^{3}-2.5 \times 10^{3}$ cells $\mathrm{ml}^{-1}$ in RPMI 1640 as measured by spectrophotometry, and an aliquot of $0.1 \mathrm{ml}$ was added to each well containing various concentrations of the antifungal drugs. Drug-free and yeast-free controls were included, and microplates were incubated at $35{ }^{\circ} \mathrm{C}$ for $72 \mathrm{~h}$.

Following the CLSI recommendations, two quality-control strains, Candida krusei (ATCC 6258) and Candida parapsilosis (ATCC 22019), were used with each test. The reproducibility of the in vitro results was assessed by determining MICs for all strains twice on two different days. The MIC end points were read visually after $72 \mathrm{~h}$ and defined for fluconazole, voriconazole, itraconazole and 5-flucytosine as the lowest drug concentration that caused a prominent decrease in growth $(50 \%)$ compared with the controls. For amphotericin B, the MIC was defined as the lowest concentration at which there was $100 \%$ inhibition of growth compared with the drug-free control wells.

Statistical analysis. Statistical differences between MIC values of various groups of strains were assessed using the Mann-Whitney test. Statistical significance was defined as $P<0.05$. Statistical analyses were performed with GraphPad Prism version 5.00 (GraphPad Software).

\section{RESULTS}

The results of antifungal susceptibility testing of $C$. neoformans var. grubii, genotype VNI/AFLPI, and C. gattii 


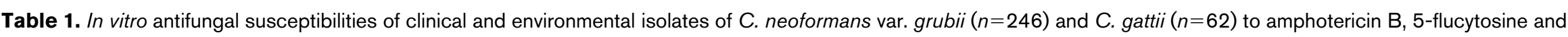
some azoles

MIC values are given in $\mu \mathrm{g} \mathrm{ml}^{-1}$.

\begin{tabular}{|c|c|c|c|c|c|c|c|c|c|c|c|c|c|c|c|c|c|c|c|c|}
\hline \multirow{2}{*}{$\begin{array}{l}\text { Test species } \\
\text { and source }\end{array}$} & \multicolumn{4}{|c|}{ Amphotericin B } & \multicolumn{4}{|c|}{ Fluconazole } & \multicolumn{4}{|c|}{ Itraconazole } & \multicolumn{4}{|c|}{ Voriconazole } & \multicolumn{4}{|c|}{ 5-Flucytosine } \\
\hline & GM & $\begin{array}{l}\text { MIC } \\
\text { range }\end{array}$ & $\mathrm{MIC}_{50}$ & $\mathrm{MIC}_{90}$ & GM & $\begin{array}{l}\text { MIC } \\
\text { range }\end{array}$ & $\mathrm{MIC}_{50}$ & $\mathrm{MIC}_{90}$ & GM & $\begin{array}{l}\text { MIC } \\
\text { range }\end{array}$ & $\mathrm{MIC}_{50}$ & $\mathrm{MIC}_{90}$ & GM & $\begin{array}{l}\text { MIC } \\
\text { range }\end{array}$ & $\mathrm{MIC}_{50}$ & $\mathrm{MIC}_{90}$ & GM & $\begin{array}{l}\text { MIC } \\
\text { range }\end{array}$ & $\mathrm{MIC}_{50}$ & $\mathrm{MIC}_{90}$ \\
\hline \multicolumn{21}{|l|}{$\begin{array}{l}\text { C. neoformans } \\
\text { var. grubii }\end{array}$} \\
\hline $\begin{array}{l}\text { Clinical } \\
(n=160)\end{array}$ & 0.235 & $0.031-1$ & 0.250 & 0.5 & 2.190 & $0.5-8$ & 2 & 4 & 0.099 & $0.031-0.250$ & 0.125 & 0.250 & 0.053 & $0.015-0.125$ & 0.062 & 0.125 & 1.450 & $0.031-64$ & 2 & 4 \\
\hline $\begin{array}{l}\text { Environmental } \\
(n=86)\end{array}$ & 0.232 & $0.062-0.5$ & 0.250 & 0.5 & 3.639 & $2-8$ & 4 & 4 & 0.142 & $0.031-0.5$ & 0.125 & 0.250 & 0.062 & $0.031-0.250$ & 0.062 & 0.125 & 3.785 & $1-16$ & 4 & 8 \\
\hline Total $(n=246)$ & 0.235 & $0.031-1$ & 0.250 & 0.5 & 2.614 & $0.5-8$ & 2 & 4 & 0.112 & $0.031-0.5$ & 0.125 & 0.250 & 0.056 & $0.015-0.125$ & 0.062 & 0.125 & 2.033 & $0.031-64$ & 2 & 8 \\
\hline \multicolumn{21}{|c|}{$\begin{array}{l}\text { C. gattii } \\
\text { serotype B }\end{array}$} \\
\hline Clinical $(n=2)$ & 0.125 & 0.125 & 0.125 & 0.125 & 1.545 & $1-2$ & 1.5 & 1.9 & 0.062 & 0.062 & 0.062 & 0.062 & 0.062 & $0.015-0.125$ & 0.07 & 0.114 & 0.773 & $0.5-1$ & 0.75 & 0.95 \\
\hline $\begin{array}{l}\text { Environmental } \\
\quad(n=60)\end{array}$ & 0.256 & $0.125-1$ & 0.250 & 0.250 & 7.379 & $2-16$ & 8 & 8 & 0.256 & $0.125-0.5$ & 0.250 & 0.5 & 0.143 & $0.062-0.250$ & 0.125 & 0.250 & 2 & $1-4$ & 2 & 2 \\
\hline Total $(n=62)$ & 0.250 & $0.125-1$ & 0.250 & 0.250 & 6.996 & $1-16$ & 8 & 8 & 0.244 & $0.062-0.5$ & 0.250 & 0.5 & 0.138 & $0.015-0.250$ & 0.125 & 0.250 & 1.934 & $0.5-4$ & 2 & 2 \\
\hline
\end{tabular}


serotype B, genotype VGI/AFLP4, are summarized in Table 1. All of the isolates of $C$. neoformans var. grubii and $C$. gattii showed low MICs for all the antifungals tested except for two clinical isolates of $C$. neoformans var. grubii, which had high MICs against 5-flucytosine (MIC $>64 \mu \mathrm{g} \mathrm{ml}^{-1}$ ). However, there were some notable differences in antifungal susceptibility of the two species and within each species depending on the origin of strains from environmental or clinical sources. Specifically, the geometric means (GMs) of MICs for the C. gattii serotype B sample were significantly higher than those of $C$. neoformans var. grubii for fluconazole (GM 6.996 vs $2.614 \mu \mathrm{g} \mathrm{ml}^{-1}, P<0.0001$ ), itraconazole (GM $\left.0.244 \mathrm{vs} 0.112 \mu \mathrm{g} \mathrm{ml}^{-1}, P<0.0001\right)$ and voriconazole (GM 0.138 vs $0.056 \mu \mathrm{g} \mathrm{ml} \mathrm{m}^{-1}, P<0.0001$ ). Similarly, the $\mathrm{MIC}_{90}$ values for C. gattii were twofold higher than those for $C$. neoformans var. grubii for fluconazole ( 8 vs $4 \mu \mathrm{g} \mathrm{ml}^{-1}$ ), itraconazole $(0.5$ vs $0.25 \mu \mathrm{g}$ $\left.\mathrm{ml}^{-1}\right)$ and voriconazole $\left(0.25 \mathrm{vs} 0.125 \mu \mathrm{g} \mathrm{ml}^{-1}\right)$. However, no statistically significant difference in susceptibility of the two Cryptococcus species was observed against amphotericin B and 5-flucytosine. Interestingly, in comparison with clinical isolates, the environmental $C$. neoformans var. grubii isolates exhibited significantly reduced susceptibility to fluconazole (GM $3.639 \mathrm{vs} 2.190 \mu \mathrm{g} \mathrm{ml}^{-1}, P<0.0001$ ), itraconazole (GM 0.142 vs $\left.0.099 \mu \mathrm{g} \mathrm{ml}^{-1}, P<0.0001\right)$ and 5-flucytosine (GM 3.785 vs $1.450 \mu \mathrm{g} \mathrm{ml}^{-1}, P<0.0001$ ).

Of the 53 serial isolates of $C$. neoformans var. grubii in this study, collected at least 1 month apart from 23 patients, four serial isolates obtained from four patients receiving antifungal therapy of amphotericin B for 3 weeks and followed by fluconazole prophylaxis ( $400 \mathrm{mg}$ daily) showed a fourfold increase in fluconazole MICs over a period of 1.5-2.5 months. However, the MIC values did not exceed $4 \mu \mathrm{g} \mathrm{ml}^{-1}$. Likewise, one serial C. neoformans var. grubii isolate from a patient showed a fourfold increase in itraconazole MIC but not in fluconazole MIC. A similar increase in amphotericin B MICs was found, which ranged from fourfold in two serial isolates to eightfold in four serial isolates over 1-3 months for strains originating from six patients who had received this antifungal drug for 3 weeks. Here again, the increase in the amphotericin B MICs did not exceed $1 \mu \mathrm{g} \mathrm{ml}^{-1}$. Interestingly, three serial isolates from three patients showed a fourfold increase in 5-flucytosine MICs, although none of the patients had received 5-flucytosine previously.

\section{DISCUSSION}

This study is noteworthy for documenting the antifungal susceptibility profiles of the highest number of C. gattii genotype VGI/AFLP4 isolates investigated in any study reported so far from India, employing the microbroth dilution method. An earlier study from India reported only the fluconazole susceptibility profiles and genotypes of 57 clinical isolates, comprising 51 C. neoformans var. grubii, genotype VNI/AFLP1, one C. neoformans var. neoformans, genotype VNIV/AFLP2, and five C. gattii, genotype VGII/
AFLP6 (Jain et al., 2005). The reported MICs ranged from 8 to $16 \mu \mathrm{g} \mathrm{ml}^{-1}$ for $C$. neoformans var. grubii and 2 to $64 \mu \mathrm{g} \mathrm{ml}^{-1}$ for C. gattii, whereas in the present study none of the 160 clinical and 86 environmental isolates of $C$. neoformans var. grubii revealed MICs $>8 \mu \mathrm{g} \mathrm{ml}^{-1}$ for $C$. neoformans var. grubii (range $0.5-8 \mu \mathrm{g} \mathrm{ml}^{-1}$ ) and 1-16 $\mu \mathrm{g}$ $\mathrm{ml}^{-1}$ for C. gattii serotype B. The low MICs observed in our clinical isolates of both species may be attributed to the fact that the majority originated from patients without history of exposure to fluconazole.

The results demonstrated that $C$. gattii isolates were significantly less susceptible to azoles than $C$. neoformans var. grubii, which agrees with several previous reports (Fernandes et al., 2003; Trilles et al., 2004; Khan et al., 2007, 2009; Gomez-Lopez et al., 2008). However, there is divergence of results concerning the antifungal susceptibility patterns of the two species in some other studies, which reported no such difference (Chen et al., 2000; Calvo et al., 2001; Morgan et al., 2006; Tay et al., 2006; Thompson et al., 2009). This divergence in results may be due to a possible lack of uniformity in the methodologies of testing adopted by different investigators. Although the Etest has been recommended as a good alternative to the CLSI microbroth dilution method for antifungal susceptibility of yeasts, the results obtained with Cryptococcus species have been inconsistent (Khan et al., 2007). It should be pointed out that the reported discrepancies in results pertain to antifungal drugs that inhibit or bind ergosterol in the cell membrane. Therapy of cryptococcosis due to C. gattii with these antifungals has also been reported to be more difficult than therapy of the disease caused by C. neoformans (Mitchell et al., 1995; Speed \& Dunt, 1995). Attention should be given to the report by Varma \& Kwon-Chung (2010), showing that $86 \%$ of the C. gattii strains expressed a heteroresistance level of $>16 \mu \mathrm{g} \mathrm{ml}{ }^{-1}$ to fluconazole compared with $46 \%$ of $C$. neoformans strains. They found that all of the clinical isolates not exposed to azoles as well as the environmental strains manifested heteroresistance to fluconazole. Furthermore, this heteroresistance of the test strains was an intrinsic character that was associated with their virulence. Thus, the inherently higher level of heteroresistance to fluconazole of C. gattii strains may be another factor that influences the MICs of the strains resulting in the variability of results of in vitro antifungal susceptibility reported in different studies.

As reported previously (Yildiran et al., 2000; van Duin et al., 2004; Souza et al., 2005; Khan et al., 2007), voriconazole exhibited the highest inhibitory activity against the isolates of C. neoformans var. grubii (GM $0.056 \mu \mathrm{g} \mathrm{ml}^{-1}$ ) and C. gattii (GM $0.138 \mu \mathrm{g} \mathrm{ml}^{-1}$ ). Itraconazole MICs were in the range of $0.25-0.5 \mu \mathrm{g} \mathrm{ml}^{-1}$ in $84 \%$ of C. gattii serotype B and in $14 \%$ of C. neoformans var. grubii isolates. This is in agreement with the results of Iqbal et al. (2010), who tested 43 clinical isolates of $C$. gattii from patients in Oregon, USA. Twenty-three per cent of their isolates had itraconazole MICs $>1 \mu \mathrm{g} \mathrm{ml}^{-1}$, whereas $55.8 \%$ revealed MICs in the range of $0.25-0.5 \mu \mathrm{g} \mathrm{ml}^{-1}$. 
Interestingly, their VGI and VGIII isolates had comparatively low fluconazole MICs, whilst the majority with MICs of $16-32 \mu \mathrm{g} \mathrm{ml}^{-1}$ were of subtype VGIIc. Similarly, all of our VGI/AFLP4 C. gattii isolates revealed MICs of $\leqslant 16 \mu \mathrm{g}$ $\mathrm{ml}^{-1}$, consistent with the report by Hagen et al. (2010) on C. gattii, which showed lower MICs for AFLP4/VGI isolates (1.401 and $2.467 \mu \mathrm{g} \mathrm{ml}^{-1}$ ) versus the higher MICs for AFLP6/VGII isolates (4.961 and $5.638 \mu \mathrm{g} \mathrm{ml}^{-1}$ ) against 5flucytosine and fluconazole, respectively. Concerning the susceptibility to 5 -flucytosine, $<2 \%$ of C. neoformans isolates have been reported as resistant to this drug prior to treatment (Scholer \& Polak, 1984), which is comparable to our results of $1.2 \%(2 / 162)$ for clinical C. neoformans var. grubii isolates. However, concern about the emergence of resistance during treatment with this drug alone has led to its use in combination with amphotericin B in patients with cryptococcosis (Perfect et al., 2010). All of the patients whose serial isolates showed an increase in azole and amphotericin B MICs were HIV-positive. It may be added in this context that relapses in patients with AIDSassociated cryptococcosis are often due to deterioration of the host immune function rather than to an increase in MICs (Witt et al., 1996). However, a rising MIC of fluconazole has been implicated in clinical relapse in patients with AIDS-associated cryptococcal meningitis (Paugam et al., 1994; Birley et al., 1995; Currie et al., 1995; Armengou et al., 1996; Berg et al., 1998; Davey et al., 1998; Aller et al., 2000).

Our significantly lower susceptibility of environmental $C$. neoformans var. grubii isolates to fluconazole, itraconazole and 5-flucytosine compared with that of the clinical isolates is in contrast to the findings of some investigators who found that antifungal susceptibility was not related to the clinical or environmental origin of strains (Franzot \& Hamdan, 1996; Moraes et al., 2003; Trilles et al., 2004). Of relevance here is the report by Soares et al. (2005) stating that a solitary isolate of $C$. neoformans var. grubii from pigeon excreta was resistant to fluconazole (MIC $64 \mu \mathrm{g}$ $\mathrm{ml}^{-1}$ ). Likewise, in another report from Brazil, one of their environmental isolates of $C$. neoformans var. neoformans was found to be resistant to itraconazole and three additional isolates exhibited high MICs of $16-32 \mu \mathrm{g} \mathrm{ml}^{-1}$ against fluconazole (Costa et al., 2010). Furthermore, a fluconazole-resistant strain isolated from an immunocompetent patient without exposure to this azole has also been reported, indicating the existence of primary resistance in environmental strains to fluconazole (Orni-Wasserlauf et al., 1999). Keeping in mind these emerging reports of resistance in environmental strains, continued surveillance for the emergence of antifungal resistance in clinical and environmental strains of $C$. neoformans and $C$. gattii is desirable for more successful therapy of cryptococcosis.

\section{ACKNOWLEDGEMENTS}

Acknowledgement is made to the Indian National Science Academy, New Delhi, for the award of a Hony Scientist position to H.S. R., and to Dr M. Rahman for assistance with statistical analysis of the data. This work was financially supported by the Department of Science and Technology, Government of India (F. no. SR/SO/HS-62/2008) and the Indian Council of Medical Research, New Delhi (HIV/50/107/ 2008).

\section{REFERENCES}

Aller, A. I., Martin-Mazuelos, E., Lozano, F., Gomez-Mateos, J., Steele-Moore, L., Holloway, W. J., Gutiérrez, M. J., Recio, F. J. \& Espinel-Ingroff, A. (2000). Correlation of fluconazole MICs with clinical outcome in cryptococcal infection. Antimicrob Agents Chemother 44, 1544-1548.

Armengou, A., Porcar, C., Mascaró, J. \& García-Bragado, F. (1996). Possible development of resistance to fluconazole during suppressive therapy for AIDS-associated cryptococcal meningitis. Clin Infect Dis 23, 1337-1338.

Berg, J., Clancy, C. J. \& Nguyen, M. H. (1998). The hidden danger of primary fluconazole prophylaxis for patients with AIDS. Clin Infect Dis 26, 186-187.

Birley, H. D., Johnson, E. M., McDonald, P., Parry, C., Carey, P. B. \& Warnock, D. W. (1995). Azole drug resistance as a cause of clinical relapse in AIDS patients with cryptococcal meningitis. Int J STD AIDS 6, 353-355.

Byrnes, E. J., III, Li, W., Lewit, Y., Ma, H., Voelz, K., Ren, P., Carter, D. A., Chaturvedi, V., Bildfell, R. J. \& other authors (2010). Emergence and pathogenicity of highly virulent Cryptococcus gattii genotypes in the northwest United States. PLoS Pathog 6, e1000850.

Calvo, B. M., Colombo, A. L., Fischman, O., Santiago, A., Thompson, L., Lazera, M., Telles, F., Fukushima, K., Nishimura, K. \& other authors (2001). Antifungal susceptibilities, varieties, and electrophoretic karyotypes of clinical isolates of Cryptococcus neoformans from Brazil, Chile, and Venezuela. J Clin Microbiol 39, 2348-2350.

Casadevall, A. \& Perfect, J. R. (1998). Cryptococcus neoformans. Washington, DC: American Society for Microbiology.

Chakrabarti, A., Sharma, A., Sood, A., Grover, R., Sakhuja, V., Prabhakar, S. \& Varma, S. (2000). Changing scenario of cryptococcosis in a tertiary care hospital in north India. Indian J Med Res 112, 56-60.

Chen, S., Sorrell, T., Nimmo, G., Speed, B., Currie, B., Ellis, D., Marriott, D., Pfeiffer, T., Parr, D. \& other authors (2000). Epidemiology and host- and variety-dependent characteristics of infection due to Cryptococcus neoformans in Australia and New Zealand. Clin Infect Dis 31, 499-508.

CLSI (2008). Reference Method for Broth Dilution Antifungal Susceptibility Testing of Yeasts, 3rd edn. Approved Standard. M27A3. Wayne, PA: Clinical and Laboratory Standards Institute.

Costa, A. K., Sidrim, J. J., Cordeiro, R. A., Brilhante, R. S., Monteiro, A. J. \& Rocha, M. F. (2010). Urban pigeons (Columba livia) as a potential source of pathogenic yeasts: a focus on antifungal susceptibility of Cryptococcus strains in Northeast Brazil. Mycopathologia 169, 207-213.

Currie, B. P., Ghannoum, M., Bessen, L. \& Casadevall, A. (1995). Decreased fluconazole susceptibility of a relapse Cryptococcus neoformans isolate after fluconazole treatment. Infect Dis Clin Pract 4, 318319.

Davey, K. G., Johnson, E. M., Holmes, A. D., Szekely, A. \& Warnock, D. W. (1998). In-vitro susceptibility of Cryptococcus neoformans isolates to fluconazole and itraconazole. J Antimicrob Chemother 42, 217-220.

Fernandes, O. de F. L., Passos, X. S., Souza, L. K. H., Miranda, A. T. B., Cerqueira, C. H. P. V. \& Silva, M. do R. R. (2003). In vitro 
susceptibility characteristics of Cryptococcus neoformans varieties from AIDS patients in Goiânia, Brazil. Mem Inst Oswaldo Cruz 98, 839841.

Franzot, S. P. \& Hamdan, J. S. (1996). In vitro susceptibilities of clinical and environmental isolates of Cryptococcus neoformans to five antifungal drugs. Antimicrob Agents Chemother 40, 822-824.

Gomez-Lopez, A., Zaragoza, O., Dos Anjos Martins, M., Melhem, M. C., Rodriguez-Tudela, J. L. \& Cuenca-Estrella, M. (2008). In vitro susceptibility of Cryptococcus gattii clinical isolates. Clin Microbiol Infect 14, 727-730.

Hagen, F., Illnait-Zaragozi, M. T., Bartlett, K. H., Swinne, D., Geertsen, E., Klaassen, C. H. W., Boekhout, T. \& Meis, J. F. (2010). In vitro antifungal susceptibilities and amplified fragment length polymorphism genotyping of a worldwide collection of 350 clinical, veterinary and environmental Cryptococcus gattii isolates. Antimicrob Agents Chemother 54, 5139-5145.

Hiremath, S. S., Chowdhary, A., Kowshik, T., Randhawa, H. S., Sun, S. \& Xu, J. (2008). Long-distance dispersal and recombination in environmental populations of Cryptococcus neoformans var. grubii from India. Microbiology 154, 1513-1524.

lqbal, N., DeBess, E. E., Wohrle, R., Sun, B., Nett, R. J., Ahlquist, A. M., Chiller, T. \& Lockhart, S. R. for the Cryptococcus gattii Public Health Working Group (2010). Correlation of genotype and in vitro susceptibilities of Cryptococcus gattii strains from the Pacific Northwest of the United States. J Clin Microbiol 48, 539-544.

Jain, N., Wickes, B. L., Keller, S. M., Fu, J., Casadevall, A., Jain, P., Ragan, M. A., Banerjee, U. \& Fries, B. C. (2005). Molecular epidemiology of clinical Cryptococcus neoformans strains from India. J Clin Microbiol 43, 5733-5742.

Khan, Z. U., Randhawa, H. S., Kowshik, T., Chowdhary, A. \& Chandy, R. (2007). Antifungal susceptibility of Cryptococcus neoformans and Cryptococcus gattii isolates from decayed wood of trunk hollows of Ficus religiosa and Syzygium cumini trees in north-western India. J Antimicrob Chemother 60, 312-316.

Khan, Z. U., Randhawa, H. S., Chehadeh, W., Chowdhary, A., Kowshik, T. \& Chandy, R. (2009). Cryptococcus neoformans serotype A and Cryptococcus gattii serotype B isolates differ in their susceptibilities to fluconazole and voriconazole. Int J Antimicrob Agents 33, 559563.

Khanna, N., Chandramuki, A., Desai, A., Ravi, V., Santosh, V., Shankar, S. K. \& Satishchandra, P. (2000). Cryptococcosis in the immunocompromised host with special reference to AIDS. Indian J Chest Dis Allied Sci 42, 311-315.

Kidd, S. E., Hagen, F., Tscharke, R. L., Huynh, M., Bartlett, K. H., Fyfe, M., MacDougall, L., Boekhout, T., Kwon-Chung, K. J. \& Meyer, W. (2004). A rare genotype of Cryptococcus gattii caused the cryptococcosis outbreak on Vancouver Island (British Columbia, Canada). Proc Natl Acad Sci U S A 101, 17258-17263.

Kwon-Chung, K. J., Boekhout, T., Fell, J. W. \& Diaz, M. (2002). Proposal to conserve the name Cryptocoocus gattii against $C$. hondurianus and C. bacillisporus (Basidiomycota, Hymenomycetes, Tremellomycetidae). Taxon 51, 804-806.

Lakshmi, V., Sudha, T., Teja, V. D. \& Umabala, P. (2007). Prevalence of central nervous system cryptococcosis in human immunodeficiency virus reactive hospitalized patients. Indian J Med Microbiol 25, 146-149.

Meyer, W., Marszewska, K., Amirmostofian, M., Igreja, R. P., Hardtke, C., Methling, K., Viviani, M. A., Chindamporn, A., Sukroongreung, S. \& other authors (1999). Molecular typing of global isolates of Cryptococcus neoformans var. neoformans by polymerase chain reaction fingerprinting and randomly amplified polymorphic DNA - a pilot study to standardize techniques on which to base a detailed epidemiological survey. Electrophoresis 20, 1790-1799.
Meyer, W., Aanensen, D. M., Boekhout, T., Cogliati, M., Diaz, M. R., Esposto, M. C., Fisher, M., Gilgado, F., Hagen, F. \& other authors (2009). Consensus multi-locus sequence typing scheme for Cryptococcus neoformans and Cryptococcus gattii. Med Mycol 47, 561-570.

Mitchell, D. H., Sorrell, T. C., Allworth, A. M., Heath, C. H., McGregor, A. R., Papanaoum, K., Richards, M. J. \& Gottlieb, T. (1995). Cryptococcal disease of the CNS in immunocompetent hosts: influence of cryptococcal variety on clinical manifestations and outcome. Clin Infect Dis 20, 611-616.

Moraes, E. M., Prímola, N. S. \& Hamdan, J. S. (2003). Antifungal susceptibility of clinical and environmental isolates of Cryptococcus neoformans to four antifungal drugs determined by two techniques. Mycoses 46, 164-168.

Morgan, J., McCarthy, K. M., Gould, S., Fan, K., Arthington-Skaggs, B., lqbal, N., Stamey, K., Hajjeh, R. A., Brandt, M. E. \& Gauteng Cryptococcal Surveillance Initiative Group (2006). Cryptococcus gattii infection: characteristics and epidemiology of cases identified in a South African province with high HIV seroprevalence, 2002-2004. Clin Infect Dis 43, 1077-1080.

Orni-Wasserlauf, R., Izkhakov, E., Siegman-Igra, Y., Bash, E., Polacheck, I. \& Giladi, M. (1999). Fluconazole-resistant Cryptococcus neoformans isolated from an immunocompetent patient without prior exposure to fluconazole. Clin Infect Dis 29, 1592-1593.

Paugam, A., Dupouy-Camet, J., Blanche, P., Gangneux, J. P., Tourte-Schaefer, C. \& Sicard, D. (1994). Increased fluconazole resistance of Cryptococcus neoformans isolated from a patient with AIDS and recurrent meningitis. Clin Infect Dis 19, 975-976.

Perfect, J. R., Dismukes, W. E., Dromer, F., Goldman, D. L., Graybill, J. R., Hamill, R. J., Harrison, T. S., Larsen, R. A., Lortholary, O. \& other authors (2010). Clinical practice guidelines for the management of cryptococcal disease: 2010 update by the Infectious Diseases Society of America. Clin Infect Dis 50, 291-322.

Randhawa, H. S., Kowshik, T., Preeti Sinha, K., Chowdhary, A., Khan, Z. U., Yan, Z., Xu, J. \& Kumar, A. (2006). Distribution of Cryptococcus gattii and Cryptococcus neoformans in decayed trunk wood of Syzygium cumini trees in north-western India. Med Mycol 44, 623630.

Randhawa, H. S., Kowshik, T., Chowdhary, A., Preeti Sinha, K., Khan, Z. U., Sun, S. \& Xu, J. (2008). The expanding host tree species spectrum of Cryptococcus gattii and Cryptococcus neoformans and their isolations from surrounding soil in India. Med Mycol 46, 823833.

Scholer, H. J. \& Polak, A. (1984). Resistance to systemic antifungal agents. In Antimicrobial Drug Resistance, pp. 393-460. Edited by L. E. Bryan. Orlando, FL: Academic Press.

Soares, M. C., Paula, C. R., Dias, A. L., Caseiro, M. M. \& Costa, S. O. (2005). Environmental strains of Cryptococcus neoformans variety grubii in the city of Santos, SP, Brazil. Rev Inst Med Trop Sao Paulo 47, 31-36.

Souza, L. K., Fernandes, O. de F. L., Kobayashi, C. C., Passos, X. S., Costa, C. R., Lemos, J. A., Souza-Júnior, A. H. \& Silva, M. do R. R. (2005). Antifungal susceptibilities of clinical and environmental isolates of Cryptococcus neoformans in Goiânia city, Goiás, Brazil. Rev Inst Med Trop Sao Paulo 47, 253-256.

Speed, B. \& Dunt, D. (1995). Clinical and host differences between infections with the two varieties of Cryptococcus neoformans. Clin Infect Dis 21, 28-34, discussion 35-36.

Tay, S. T., Tanty Haryanty, T., Ng, K. P., Rohani, M. Y. \& Hamimah, H. (2006). In vitro susceptibilities of Malaysian clinical isolates of Cryptococcus neoformans var. grubii and Cryptococcus gattii to five antifungal drugs. Mycoses 49, 324-330. 
Thakur, R., Sarma, S. \& Kushwaha, S. (2008). Prevalence of HIVassociated cryptococcal meningitis and utility of microbiological determinants for its diagnosis in a tertiary care center. Indian J Pathol Microbiol 51, 212-214.

Thompson, G. R., III, Wiederhold, N. P., Fothergill, A. W., Vallor, A. C., Wickes, B. L. \& Patterson, T. F. (2009). Antifungal susceptibilities among different serotypes of Cryptococcus gattii and Cryptococcus neoformans. Antimicrob Agents Chemother 53, 309-311.

Trilles, L., Fernández-Torres, B., Lazéra, M. dos S., Wanke, B. \& Guarro, J. (2004). In vitro antifungal susceptibility of Cryptococcus gattii. J Clin Microbiol 42, 4815-4817.

van Duin, D., Cleare, W., Zaragoza, O., Casadevall, A. \& Nosanchuk, J. D. (2004). Effects of voriconazole on Cryptococcus neoformans. Antimicrob Agents Chemother 48, 2014-2020.
Varma, A. \& Kwon-Chung, K. J. (2010). Heteroresistance of Cryptococcus gattii to fluconazole. Antimicrob Agents Chemother 54, 2303-2311.

Witt, M. D., Lewis, R. J., Larsen, R. A., Milefchik, E. N., Leal, M. A., Haubrich, R. H., Richie, J. A., Edwards, J. E., Jr \& Ghannoum, M. A. (1996). Identification of patients with acute AIDS-associated cryptococcal meningitis who can be effectively treated with fluconazole: the role of antifungal susceptibility testing. Clin Infect Dis 22, 322-328.

Yildiran, S. T., Saracli, M. A., Fothergill, A. W. \& Rinaldi, M. G. (2000). In vitro susceptibility of environmental Cryptococcus neoformans variety neoformans isolates from Turkey to six antifungal agents, including SCH56592 and voriconazole. Eur J Clin Microbiol Infect Dis 19, 317-319. 